\title{
A Simplified Model for Dynamic Response Analysis of Framed Self-Centering Wall Structures under Seismic Excitations
}

\author{
Xiaobin $\mathrm{Hu} \mathbb{D}^{1,2}$ Chen $\mathrm{Lu} \mathbb{D}^{1},{ }^{1}$ and Xiaoqing $\mathrm{Zhu} \mathbb{D}^{1}$ \\ ${ }^{1}$ School of Civil Engineering, Wuhan University, Wuhan 430072, China \\ ${ }^{2}$ Engineering Research Center of Urban Disasters Prevention and Fire Rescue Technology of Hubei Province, Wuhan 430072, \\ China
}

Correspondence should be addressed to Xiaoqing Zhu; whuzxq@whu.edu.cn

Received 9 January 2019; Revised 26 February 2019; Accepted 26 March 2019; Published 15 April 2019

Academic Editor: Salvatore Russo

Copyright (C) 2019 Xiaobin Hu et al. This is an open access article distributed under the Creative Commons Attribution License, which permits unrestricted use, distribution, and reproduction in any medium, provided the original work is properly cited.

\begin{abstract}
This paper presents a simplified model for dynamic response analysis of the framed self-centering wall (FSCW) structure under seismic excitations. In the analysis model, the frame is equivalent as a single-degree-of-freedom system and collaborates with the self-centering (SC) wall to resist lateral loads. By way of pushover analysis of a typical FSCW structure, the proposed analysis model is validated by comparing the analysis results with those obtained from the finite element analysis method. Using the analysis model, motion equations of the FSCW structure under seismic excitations are established and solved through numerical simulations. Finally, a comprehensive parametric study is conducted to investigate the effects of a variety of design parameters on seismic responses of the FSCW structure. It shows that improving the yield force or elastic stiffness of the frame can help greatly lessen seismic responses of the FSCW structure in terms of the rotation angle of the SC wall.
\end{abstract}

\section{Introduction}

In recent decades, the self-centering (SC) structures have attracted a lot of attention from the earthquake engineering community. After strong ground shaking, they undergo almost no residual deformation and can resume normal service with little or no rehabilitation. Several types of SC structural systems have been proposed, such as SC wall structures, SC frame structures, and SC braced frame structures. As a typical SC structure, the SC wall is mainly composed of three parts: wall, posttensioned (PT) tendons, and dampers. It gains the self-centering ability usually by making use of the gap-opening behavior of the horizontal connections at the base or along the height of the wall [1].

Extensive studies have been conducted on the dynamic behavior or seismic performance of the SC wall by theoretical, numerical, and experimental methodologies. Two types of analysis models, i.e., the rigid body model and finite element (FE) model, have been proposed in the theoretical or numerical investigations. For the former one, the SC wall is treated as a rigid body, the PT tendon is represented by an elastic spring, and the dampers are simulated by elastoplastic springs [2]. Using this model as well as referring to the work concerning rocking response analysis of the rigid block under ground motions [3-7], $\mathrm{Hu}$ et al. [8] investigated rocking responses of the $\mathrm{SC}$ wall under seismic excitations. Differently, for the FE model, the wall is simulated by fiber beam-column elements $[9,10]$ or diagonal struts $[11,12]$, while the rocking behavior at the base is simulated by a group of contact springs. In addition to the above studies, some scholars investigated experimentally or numerically the seismic performance of the SC precast concrete walls [13-22] and SC confined masonry walls $[11,12]$. The research outcomes generally demonstrate that the SC wall exhibits minor damage with little or no residual displacements under cyclic loading or seismic excitations. Moreover, the addition of dampers can substantially enhance the energy dissipation capacity of the SC wall.

Recently, the framed self-centering wall (FSCW) structure has emerged by combining the SC wall with the frame. Two types of FSCW structures are mainly concerned, i.e., one adopting the rocking wall [23-26] and the other one adopting the stepping wall [27-29], as shown in Figure 1. For the latter one, only a few studies have been carried out on 


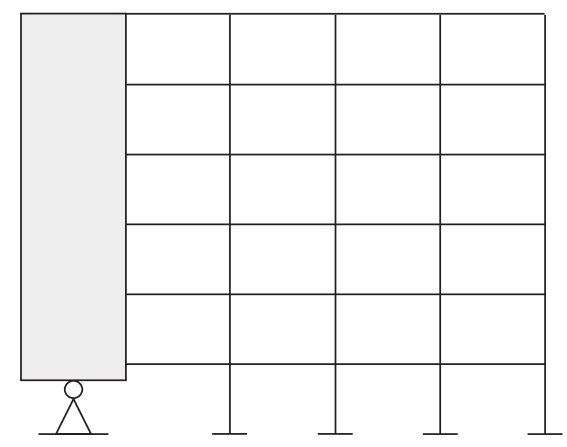

(a)

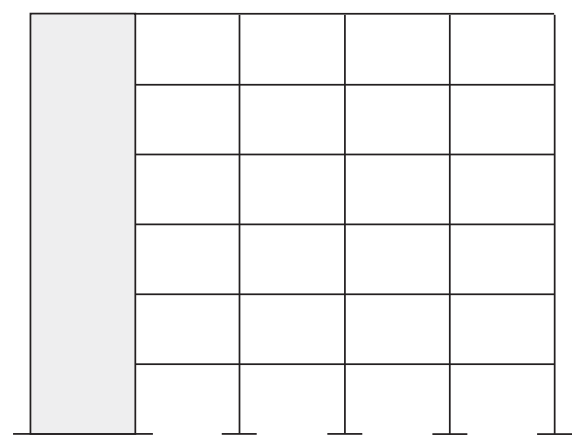

(b)

FIGURE 1: Illustration of two types of FSCW structures. (a) One adopting the rocking wall. (b) One adopting the stepping wall.

its seismic performance mainly through the numerical analysis method. For example, Ajrab et al. [27] performed nonlinear time-history analyses of the FSCW structure equipped with additional PT tendons and dampers. The results show that the interstory drifts of the FSCW structure are more uniform than those of the framed fixed-based wall structure. In addition, Zibaei and Mokari [28] conducted a comparative study on seismic performance of RC frames, RC frames with shear wall, and RC frames with controlled rocking wall by means of pushover analysis. The results show that, for the RC frames with rocking wall system, not only plastic hinge formation and interstory drifts are well distributed, but also energy dissipation and displacement ductility are increased. Besides, $\mathrm{Hu}$ et al. [29] compared seismic responses of the $\mathrm{RC}$ frame before and after retrofitted by SC walls through nonlinear time-history analysis. It shows that the SC wall can effectively reduce seismic responses of the original RC frame structure while incurring little or no residual deformation. More recently, Grigorian et al. [30] proposed a methodology for developing earthquake-resilient structures by introducing a rocking core-moment frame as the lateral resisting component of a gravity-resisting structure that is detailed to recenter while sustaining large lateral deformations.

From the above literature review, it can be seen that the limited studies regarding the FSCW structure usually involve nonlinear FE analysis. It may be time-consuming especially in case of analyzing the complex structure. Furthermore, there are still uncertainties in establishing the FE model, for example, how to determine the contact parameters to realistically replicate the gap-opening behavior of the connections. In view of these issues, this paper is mainly aimed to develop a simplified analysis model of the FSCW structure under lateral loading. After validated by the FE analysis method, this model is further employed to establish motion equations of the FSCW structure under seismic excitations. By means of numerical simulation, seismic responses of the FSCW structure are obtained. Finally, a comprehensive parametric study is carried out to investigate the influences of a variety of design parameters, which mainly include those concerning the PT tendon, the dampers and the frame, on seismic responses of the FSCW structure.

\section{Simplified Analysis Model of FSCW Structures}

2.1. General Analysis Model. As illustrated in Figure 2(a), the FSCW structure mainly comprises three parts: the SC wall, the frame, and the linking beam. In this study, only the moment frame is considered. It is assumed that these three components are lumped in the plane along the loading direction, as shown in Figure 2(b). Furthermore, the PT tendon is supposed to be installed vertically along the center line of the SC wall, and the dampers are placed at two ends of the bottom of the wall.

Since the frame can be represented as a multi-degree-offreedom (MDOF) system, a general analysis model of the FSCW structure can thus be formed as seen in Figures 2(c)-2(d). Depending on whether the constraints between the linking beam and the SC wall are considered or not, the analysis model can be categorized into two types, i.e., the pin-jointed system (Figure 2(c)) and the rigid-jointed system (Figure $2(\mathrm{~d})$ ). In the figures, $h, b$, and $l$ represent the height, the width, and the diagonal length of the SC wall, respectively, with $\alpha$ being the angle between the wall diagonal and height. In addition, $k_{j}$ and $h_{j}$ are the stiffness and the height relative to the ground of the $j$ th $(j=1, \ldots, n)$ storey of the frame, respectively, where $n$ is the number of storeys.

\subsection{Simplified Analysis Model}

2.2.1. Formulation of the Simplified Model. According to the displacement-based seismic design philosophy [31, 32], the MDOF system can be equivalent as a single-degree-offreedom (SDOF) system, as shown in Figure 3, where $m_{j}$, $F_{j}$, and $\delta_{j}$ denote the mass, horizontal force, and lateral displacement of the $j$ th storey of the MDOF system. The parameters concerning the equivalent SDOF system are determined as follows:

$$
\begin{gathered}
h_{\mathrm{eq}}=\frac{\sum_{j=1}^{n}\left(m_{j} \delta_{j} h_{j}\right)}{\sum_{j=1}^{n}\left(m_{j} \delta_{j}\right)}, \\
m_{\mathrm{eq}}=\frac{\sum_{j=1}^{n}\left(m_{j} \delta_{j}\right)}{\delta_{\mathrm{eq}}},
\end{gathered}
$$




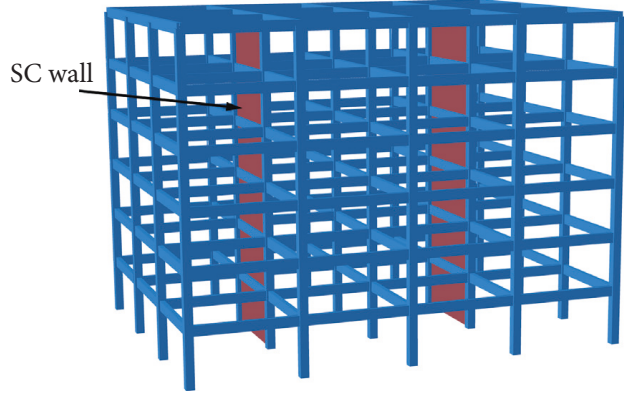

(a)

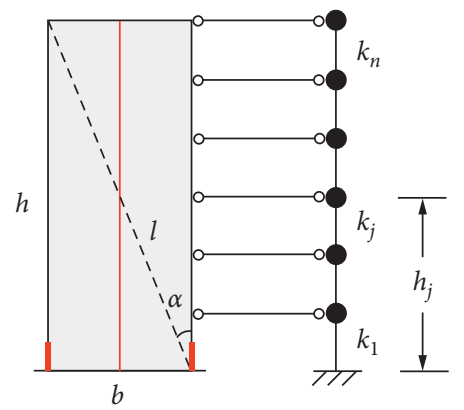

(c)

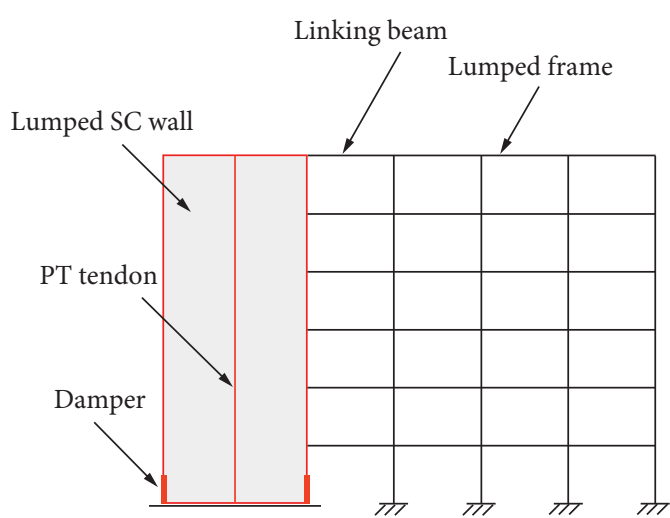

(b)

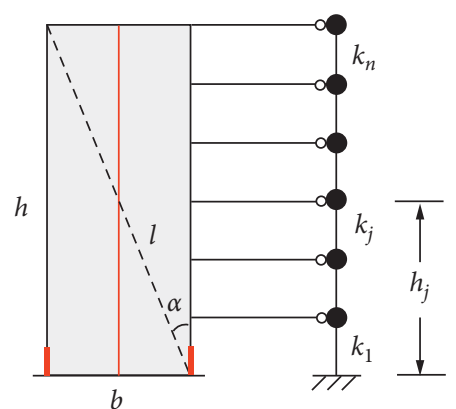

(d)

FIgURE 2: General analysis model of the FSCW structure. (a) 3D view of a typical FSCW structure. (b) 2D representation of a FSCW structure. (c) Pin-jointed system. (d) Rigid-jointed system.
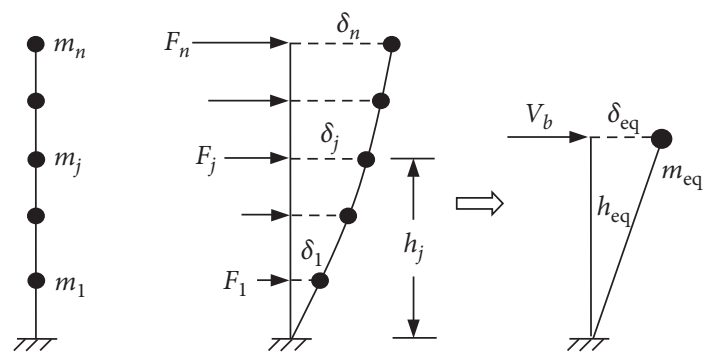

Figure 3: Conversion of a MDOF system into an equivalent SDOF system.

$$
\delta_{\mathrm{eq}}=\frac{\sum_{j=1}^{n}\left(m_{j} \delta_{j}^{2}\right)}{\sum_{j=1}^{n}\left(m_{j} \delta_{j}\right)},
$$

where $h_{\mathrm{eq}}, m_{\mathrm{eq}}$, and $\delta_{\mathrm{eq}}$ represent the equivalent height, equivalent mass, and equivalent displacement of the SDOF system, respectively.

By converting the MDOF system into a SDOF system (Figure 3), the general analysis model of the FSCW structure (Figures 2(c) and 2(d)) can be further simplified as shown in Figure 4. Furthermore, considering that the lateral displacement curve of the frame is approximately linear along the height [27-29], we can have

$$
\delta_{j}=\theta h_{j}, \quad j=1,2, \ldots, n,
$$

where $\theta$ represents the storey drift which is constant along the height of the frame. Thereby, for the $n$th storey, it has

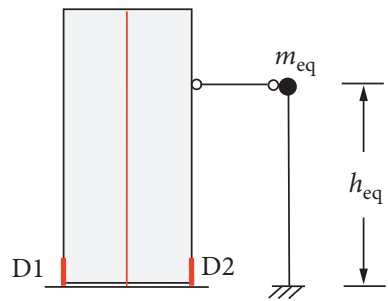

(a)

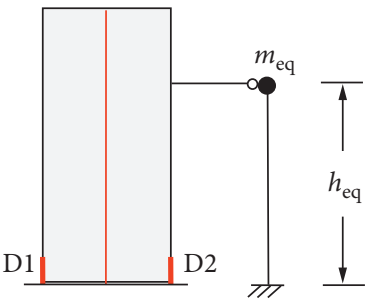

(b)
FIGURE 4: Simplified analysis model of the FSCW structure. (a) Pin-jointed system. (b) Rigid-jointed system.

$$
\delta_{n}=\theta h_{n}
$$

Substituting equations (2) and (3) in equations (1a)-(1c) can yield

$$
\begin{gathered}
h_{\mathrm{eq}}=\frac{\sum_{j=1}^{n}\left(m_{j} h_{j}^{2}\right)}{\sum_{j=1}^{n}\left(m_{j} h_{j}\right)}, \\
m_{\mathrm{eq}}=\frac{\left(\sum_{j=1}^{n} m_{j} h_{j}\right)^{2}}{\sum_{j=1}^{n}\left(m_{j} h_{j}^{2}\right)}, \\
\delta_{\mathrm{eq}}=\frac{\sum_{j=1}^{n}\left(m_{j} h_{j}^{2}\right)}{\sum_{j=1}^{n}\left(m_{j} h_{j}\right)} \frac{\delta_{n}}{h_{n}} .
\end{gathered}
$$

From the above equations, it can be clearly seen that $h_{\mathrm{eq}}$, $m_{\text {eq }}$, and $\delta_{\text {eq }}$ regarding the equivalent SDOF system rely only 
on the values of $h_{j}, m_{j}(j=1, \ldots, n)$, and $\delta_{n}$ corresponding to the original MDOF system.

2.2.2. Nonlinear Analysis Parameters of the Frame. To conduct nonlinear analysis of the FSCW structure under lateral loading, the nonlinear behavior of the frame needs to be explicitly taken into account. For simplification purpose, the hysteresis model of the frame is assumed to be bilinear as shown in Figure 5 , where $k_{\mathrm{f}}, f_{\mathrm{y}}$, and $\eta$ represents the elastic stiffness, the yield force, and the postyield stiffness coefficient of the frame. Actually, the bilinear hysteresis is usually adopted to represent the general structural behavior especially for the SDOF system irrespective of the materials involved.

In order to obtain nonlinear parameters of the frame, the following procedures can be implemented: (1) Conduct pushover analysis of the frame and obtain the capacity curve, i.e., the base shear vs. top displacement curve, as shown in Figure 6(a). Although various lateral load patterns, such as the inverted triangular load, uniform load, or concentrated load, can be considered in pushover analysis, the one that makes the lateral displacement approximately linear along the height is recommended here. (2) Convert the capacity curve into the force vs. displacement curve corresponding to the equivalent SDOF system, as shown in Figure 6(b), by utilizing equation (4c) as well as the assumption that the frame and the equivalent system have the same base shear. (3) Extract the values of $k_{\mathrm{f}}, f_{\mathrm{y}}$, and $\eta$ directly from the curve approximately by the plotting method, as seen in Figure 6(b).

\section{Verification of the Proposed Analysis Model}

3.1. Details of the Analyzed FSCW Structure. A representative six-storey concrete FSCW structure is analyzed in this section. Figure 7 gives the geometry dimensions and reinforcement details of the FSCW structure. In addition, the thickness of the SC wall is $240 \mathrm{~mm}$. The compressive strength and elastic modulus of the concrete are $30 \mathrm{MPa}$ and $3.0 \times 10^{4} \mathrm{MPa}$, respectively. The yield strength and elastic modulus of the longitudinal rebars in the frame and the linking beams are $400 \mathrm{MPa}$ and $2 \times 10^{5} \mathrm{MPa}$, respectively. The PT tendon with an effective radius of $10.8 \mathrm{~mm}$ is arranged along the center line of the wall. The elastic modulus of the tendon and its initial stress are $2 \times 10^{5} \mathrm{MPa}$ and 139.5 MPa, respectively. For the dampers, the yield force and elastic stiffness are set to be $100 \mathrm{kN}$ and $45 \mathrm{kN} / \mathrm{mm}$, respectively.

3.2. FE Modeling of the FSCW Structure. In this section, two different FE models of the FSCW structure are established in the software ABAQUS [33]: one involves the original FSCW structure, and another one uses the proposed simplified analysis model.

3.2.1. General FE Model. Figure 8(a) shows the overall FE model of the original FSCW structure. The SC wall is modeled by the shell element S4R, and its material is set to be

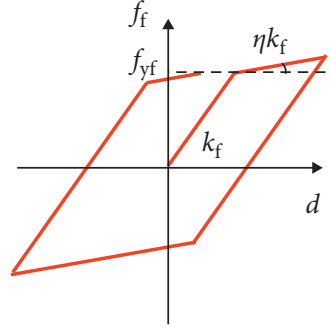

Figure 5: Hysteresis model of the frame.

elastic since the wall usually exhibits minor or no damage during lateral loading. The foundation is simulated by the solid element C3D8R, and its material is also set to be elastic. Note that the uplift of the foundation may occur due to the compliance effects of the underlying material and have a great impact on the rocking behavior of the SC wall; however, it is beyond the scope of this study and thus neglected here. The interaction between the SC wall and the foundation is considered by defining the surface-to-surface contact, as shown in Figure 8(b). The dampers are simulated by axial connectors, and the elastic-perfectly plastic constitutive relation is adopted. Besides, the PT tendon is simulated by the beam element B31 with one end tied to the top of the wall and another one anchored directly to the foundation, and its material is also set to be elastic.

The frame and the linking beams are modeled using the beam element $\mathrm{B} 31$. The concrete constitutive relation shown in Figure 8(c), which ignores its tensile strength [34], is used here. By way of the user material subroutine [33], the above concrete constitutive relation is programmed into ABAQUS. The longitudinal rebars are simulated by adding the keyword * rebar in the input file, and the elastic-perfectly plastic constitutive relation is adopted.

It is worth noting that the connection between the SC wall and the linking beam needs to be modeled properly according to the type of the FSCW structure. For the rigidjointed system, the SC wall and the linking beams are directly merged where they intersect; for the pin-jointed system, the above merging operation is first conducted and then the keyword $*$ release is used to release the constraints between the SC wall and the linking beams.

3.2.2. Simplified FE Model. Figure 9 gives the simplified FE model of the FSCW structure, where the frame is represented by an equivalent SDOF system and simulated by a translator connector. To obtain nonlinear analysis parameters of the frame, pushover analysis of the frame is first carried out, and the resulted capacity curve is shown in Figure 10. Following the procedure stated in Section 2.2.2, the parameters of the SDOF system can be obtained as follows: $m_{\mathrm{eq}}=4.73 \times 10^{4} \mathrm{~kg}, h_{\mathrm{eq}}=12.8 \mathrm{~m}, k_{\mathrm{f}}=4375 \mathrm{kN} / \mathrm{m}$, $f_{\mathrm{yf}}=400 \mathrm{kN}$, and $\eta=0.1$.

3.3. Comparison between the Analysis Results. Utilizing the above two FE models, pushover analyses of the FSCW structure are conducted, respectively. To save space, only pin-jointed connection between the linking beam and the SC 


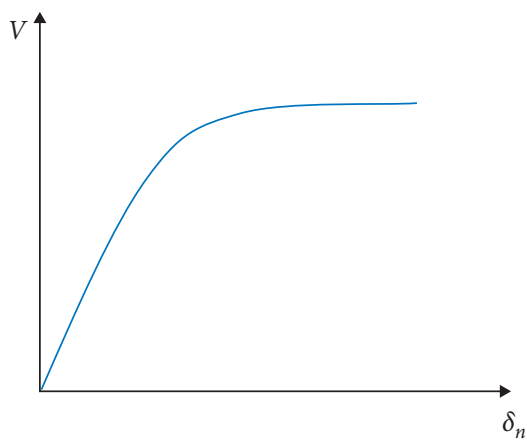

(a)

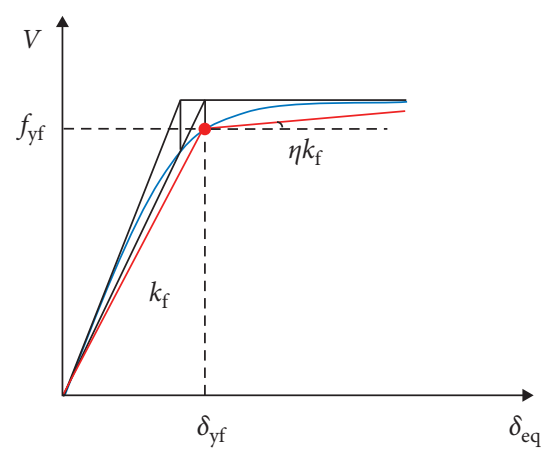

(b)

FIgURe 6: Nonlinear parameters of the frame. (a) Capacity curve of the frame. (b) Force vs. displacement curve of the equivalent SDOF system.
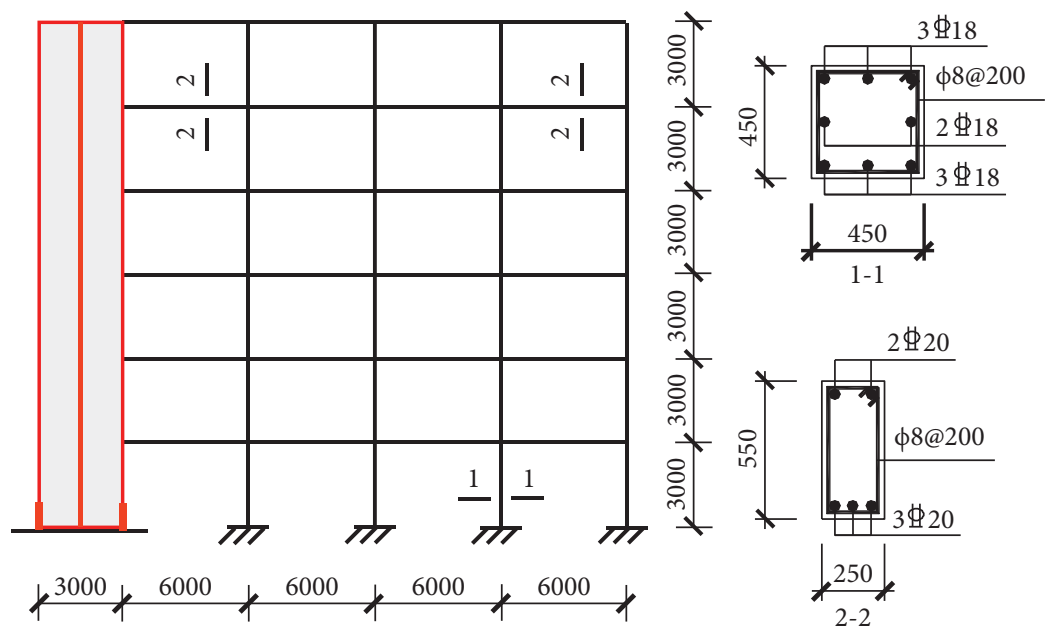

FIgURE 7: Details of the analyzed FSCW structure (length unit: $\mathrm{mm}$ ).

wall is considered here. In addition, it is supposed that the concentrated force is applied laterally on the top of the SC wall.

Figure 11 shows the capacity curves obtained using the two models. It can be seen that on the whole, the two curves are close especially during the elastic stage. Beyond the elastic stage, although obvious difference can be observed, the maximum errors between the base shears obtained from the two models are less than $11 \%$. The errors may mainly originate from the inaccuracy of the parameters related to the equivalent SDOF system. By adjusting these parameters, better matches between the results obtained from the two models can be available. Therefore, it can be concluded to some extent that the proposed simplified analysis model of the FSCW structure is capable of approximately capturing the nonlinear behavior of the FSCW structure under lateral loading, while having the appealing advantage of simplicity.

\section{Dynamic Response Analysis of the FSCW Structure}

In this section, the above simplified analysis model is further utilized to establish motion equations of the FSCW structure under seismic excitations. Without loss of generality, only the pin-jointed system shown in Figure 4(a) is taken into account. Based on the motion equations, the numerical simulation model is constructed using the MATLAB/ Simulink software, and the dynamic responses are obtained.

4.1. Motion Equations of the FSCW Structure. The SC wall of the FSCW structure is treated as a rigid body, which is widely used in the previous relevant studies and has been verified by some experiments (e.g., among others, [21, 22]). In addition, it is supposed that the SC wall only rotates about points $\mathrm{O}$ or $\mathrm{O}^{\prime}$ without sliding under seismic excitations, as shown in Figures 12(a) and 13(a). In the two figures, $\theta$ is the rotation angle of the SC wall, which is assumed to be positive for the wall rotating about point $\mathrm{O}$ and negative in case of rotating about $\mathrm{O}^{\prime}$. Besides, the damping associated with the system is neglected for simplification.

4.1.1. Rotating about $\mathrm{O}^{\prime}$. When the SC wall rotates about point $\mathrm{O}^{\prime}$, as shown in Figure 12(a), the following moment equilibrium equation can be established according to the D'Alembert principle: 


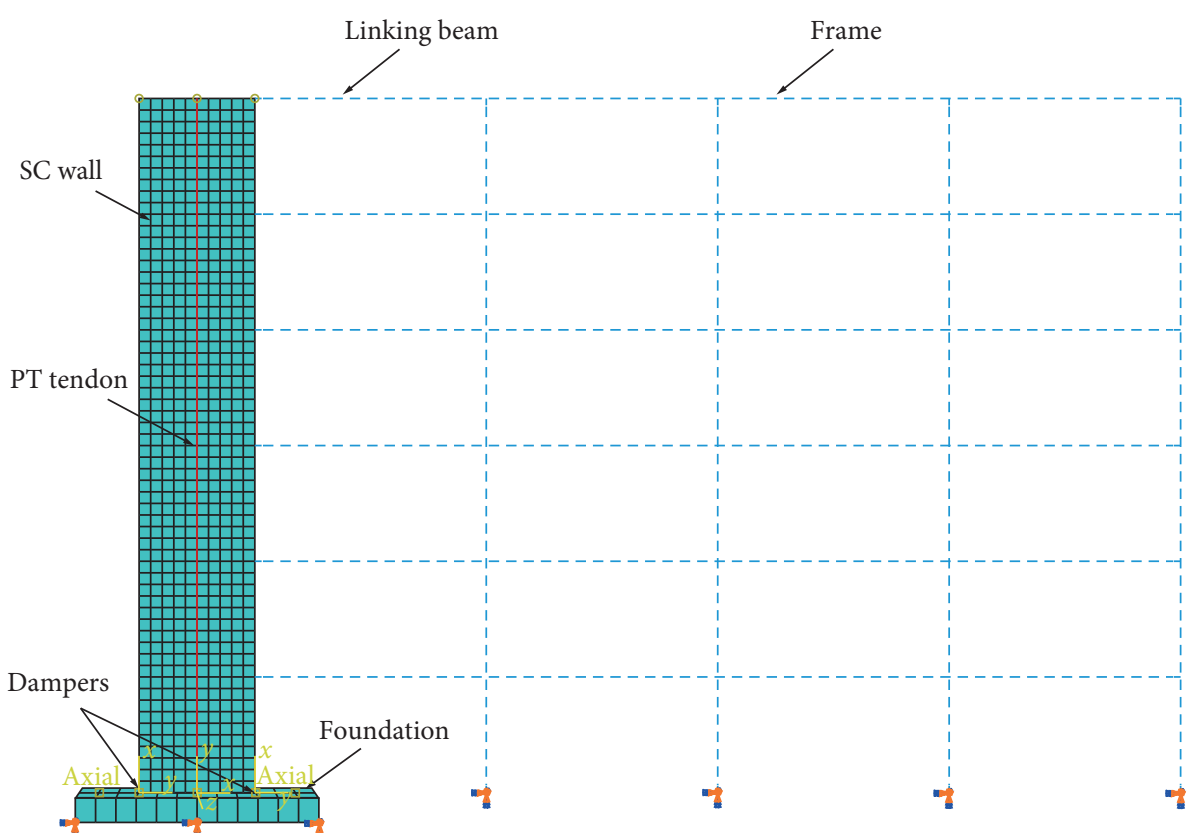

(a)

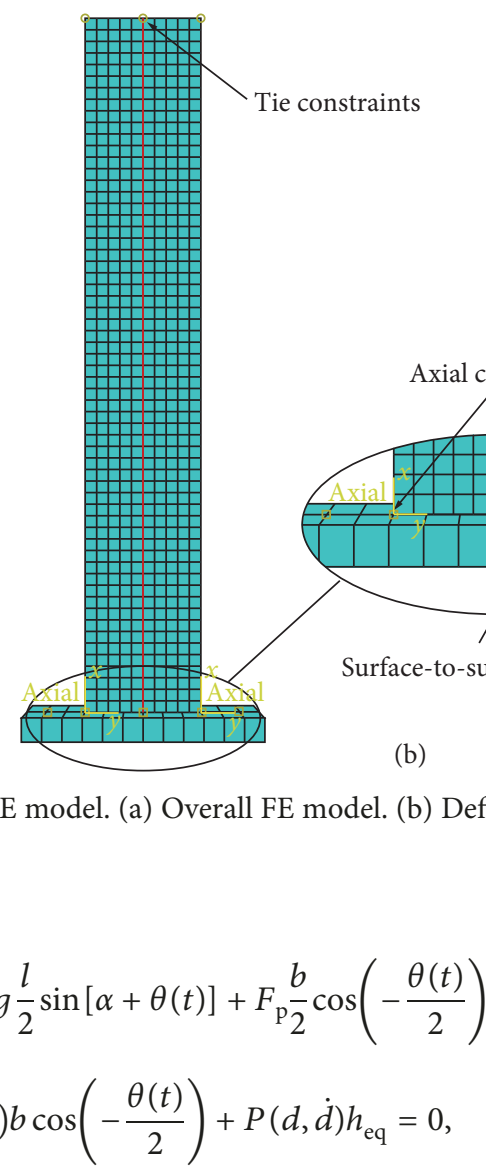

where $M_{\mathrm{I}}$ and $F_{\mathrm{It}}$ are the inertial moment and the tangential inertial force of the SC wall, respectively; $m$ is the mass of the wall; $F_{\mathrm{p}}$ is the force in the PT tendon; $f_{1}\left(x_{1}, \dot{x}_{1}\right)$ is the restoring force of the right damper, where $x_{1}$ is the displacement of the damper and $\dot{x}_{1}$ is the corresponding velocity; and $P(d, \dot{d})$ is the lateral force interacting between the SC wall and the frame, where $d$ is the lateral displacement of the frame and $\dot{d}$ is the corresponding velocity.

It is worth noting that only the lateral displacement of the linking beam end connected to the SC wall is considered to facilitate the above formulation. It is approximately valid in case of small rotation of the SC wall as well as considering that the width of the wall is usually smaller than its height. Under this circumstance, the linking beam primarily plays a role of delivering the lateral force between the SC wall and the frame. In addition, the hypothesis that the SC wall rocks about its tips, which arises from the aforementioned rigid body assumption, may seem to be unrealistic as reported in some references (see, among 


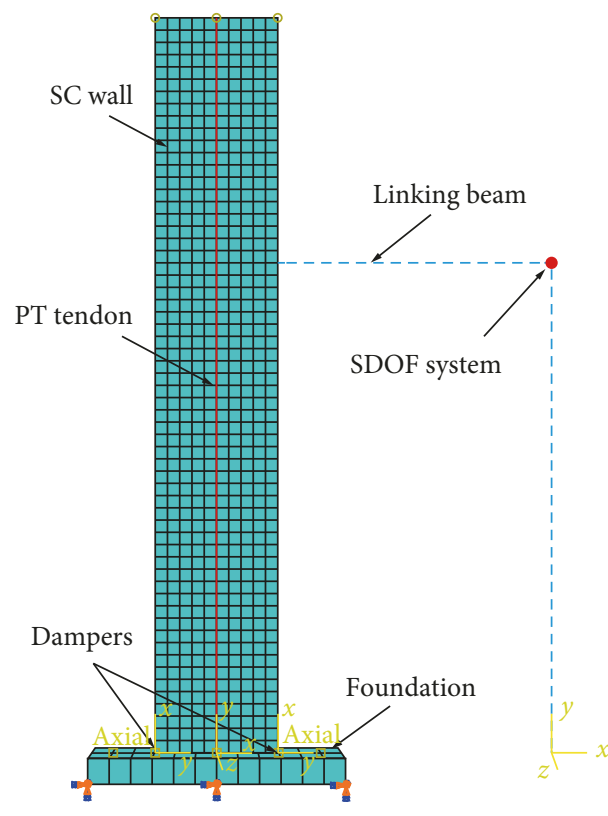

Figure 9: Simplified FE model.

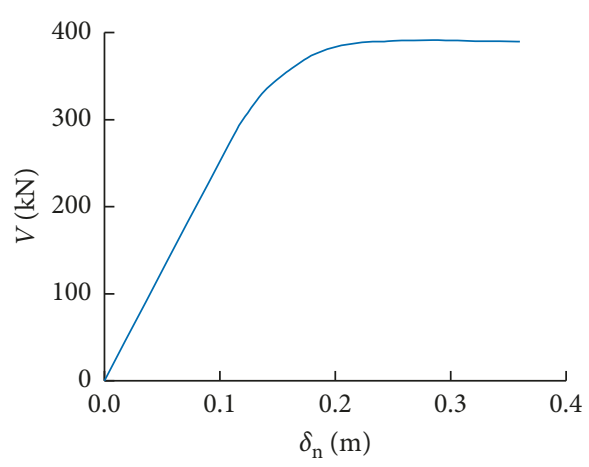

FIgURE 10: Capacity curve of the frame.

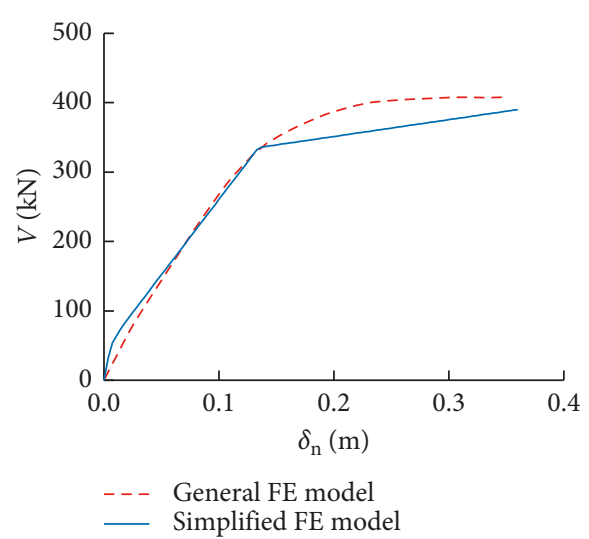

FIGURE 11: Capacity curves of the FSCW structure obtained using the two models.

others, [35]). Although some modifications to this assumption considering real conditions may yield more precise or meaningful results, it is beyond the scope of this study and can be further investigated in the future.

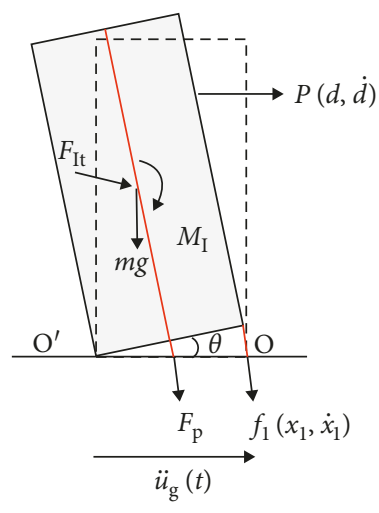

(a)

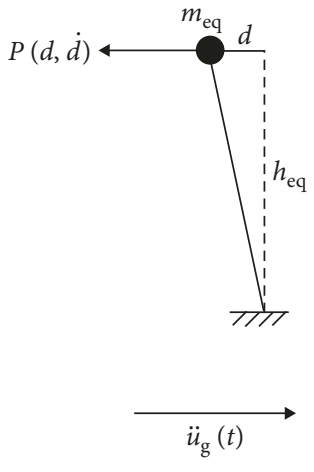

(b)
FIgURE 12: Mechanical analysis of the FSCW structure when the SC wall rotates about point $\mathrm{O}^{\prime}$ : (a) SC wall; (b) frame.

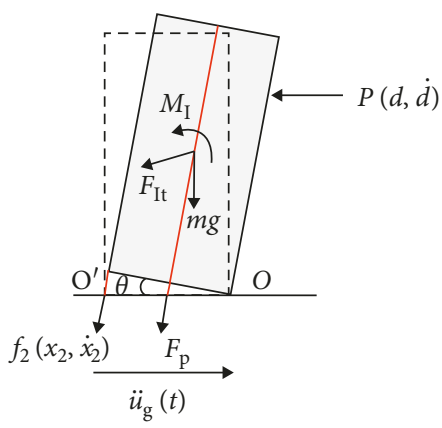

(a)

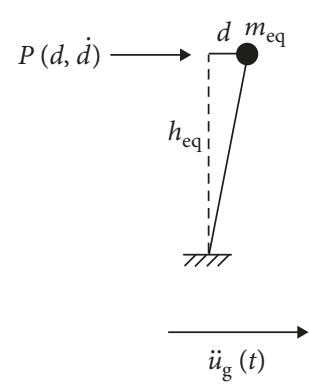

(b)
FIGURE 13: Mechanical analysis of the FSCW structure when the SC wall rotates about point $\mathrm{O}^{\prime}$ : (a) SC wall; (b) frame.

As shown in Figure 12(a), the tangential inertial force and the inertial moment of the SC wall can be determined as

$$
\begin{aligned}
& F_{\mathrm{It}}=m\left\{-\ddot{\theta} l-\ddot{u}_{\mathrm{g}}(t) \cos [\alpha+\theta(t)]\right\}, \\
& M_{\mathrm{I}}=-I_{\mathrm{cg}} \ddot{\theta}(t),
\end{aligned}
$$

where $I_{\mathrm{cg}}$ is the moment of inertia of the wall about its centroid, $I_{\mathrm{cg}}=(1 / 12) m l^{2}$. In addition, using the geometry relation, the force $F_{\mathrm{p}}$ in the PT tendon can be easily obtained as

$$
F_{\mathrm{p}}=F_{\mathrm{p} 0}-k_{\mathrm{p}} b \sin \frac{\theta(t)}{2},
$$

where $F_{\mathrm{p} 0}$ and $k_{\mathrm{p}}$ are the initial force and the elastic stiffness of the tendon, respectively.

As shown in Figure 12(b), the horizontal force applied on the frame can be obtained as

$$
P(d, \dot{d})=m_{\mathrm{eq}}\left[-\ddot{d}-\ddot{u}_{\mathrm{g}}(t)\right]-F(d, \dot{d}),
$$

where $F(d, \dot{d})$ is the restoring force of the frame.

Substituting equations (6)-(9) in equation (5), we can have 


$$
\begin{aligned}
& I_{0} \ddot{\theta}(t)+m g \frac{l}{2} \sin [-\alpha-\theta(t)]-F_{\mathrm{p} 0} \frac{b}{2} \cos \frac{\theta(t)}{2}+k_{\mathrm{p}} \frac{b^{2}}{4} \sin \theta(t) \\
& \quad-f_{1}\left(x_{1}, \dot{x}_{1}\right) b \cos \frac{\theta(t)}{2} \\
& \quad+h_{\mathrm{eq}}\left[m_{\mathrm{eq}} h_{\mathrm{eq}} \ddot{\theta}(t)+m_{\mathrm{eq}} \ddot{u}_{g}(t)+F(d, \dot{d})\right] \\
& \quad=-m \ddot{u}_{\mathrm{g}}(t) \frac{l}{2} \cos [-\alpha-\theta(t)],
\end{aligned}
$$

where $I_{0}$ is the moment of inertia of the wall about point $\mathrm{O}^{\prime}$, $I_{0}=I_{\mathrm{cg}}+m\left(l^{2} / 4\right)$.

4.1.2. Rotating about $O$. When the SC wall rotates about point $\mathrm{O}$, as shown in Figure 13(a), the following moment equilibrium equation can be established similarly:

$$
\begin{aligned}
M_{\mathrm{I}} & +F_{\mathrm{It}} \frac{l}{2}+m g \frac{l}{2} \sin [\alpha-\theta(t)]+f_{2}\left(x_{2}, \dot{x}_{2}\right) b \cos \left(\frac{\theta(t)}{2}\right) \\
& +F_{\mathrm{p}} \frac{b}{2} \cos \left(\frac{\theta(t)}{2}\right)+P(d, \dot{d}) h_{\mathrm{eq}}=0,
\end{aligned}
$$

where $f_{2}\left(x_{2}, \dot{x}_{2}\right)$ is the restoring force of the left damper, $x_{2}$ is the displacement of the damper, and $\dot{x}_{2}$ is the corresponding velocity. Under this circumstance, equations (6)-(9) turn into

$$
\begin{aligned}
F_{\mathrm{It}} & =m\left\{\ddot{\theta}(t) \frac{l}{2}+\ddot{u}_{\mathrm{g}}(t) \cos [\alpha-\theta(t)]\right\}, \\
M_{\mathrm{I}} & =I_{\mathrm{cg}} \ddot{\theta}(t), \\
F_{\mathrm{p}} & =F_{\mathrm{p} 0}+k_{\mathrm{p}} b \sin \frac{\theta(t)}{2}, \\
P(d, \dot{d}) & =m_{\mathrm{eq}}\left[\ddot{d}+\ddot{u}_{\mathrm{g}}(t)\right]+F(d, \dot{d}),
\end{aligned}
$$

respectively. From equations (11)-(15), we can have

$$
\begin{aligned}
& I_{0} \ddot{\theta}(t)+m g \frac{l}{2} \sin [\alpha-\theta(t)]+F_{\mathrm{p} 0} \frac{b}{2} \cos \frac{\theta(t)}{2}+k_{\mathrm{p}} \frac{b^{2}}{4} \sin \theta(t) \\
& \quad+f_{2}\left(x_{2}, \dot{x}_{2}\right) b \cos \frac{\theta(t)}{2} \\
& \quad+h_{\mathrm{eq}}\left[m_{\mathrm{eq}} h_{\mathrm{eq}} \ddot{\theta}(t)+m_{\mathrm{eq}} \ddot{u}_{g}(t)+F(d, \dot{d})\right] \\
& \quad=-m \ddot{u}_{\mathrm{g}}(t) \frac{l}{2} \cos [\alpha-\theta(t)] .
\end{aligned}
$$

Equations (10) and (16) can be combined into the following compact form:

$$
\begin{aligned}
& \ddot{\theta}(t)=-\frac{1}{I_{0}+m_{\mathrm{eq}} h_{\mathrm{eq}}^{2}}\left\{m g \frac{l}{2} \sin [\alpha \operatorname{sgn}[\theta(t)]-\theta(t)]\right. \\
& +\operatorname{sgn}[\theta(t)] \frac{F_{\mathrm{p} 0} b}{2} \cos \frac{\theta(t)}{2}+\frac{k_{\mathrm{p}} b^{2}}{4} \sin \theta(t) \\
& +\operatorname{sgn}[\theta(t)]\left\{\varepsilon[-\theta(t)] f_{1}(x, \dot{x})+\varepsilon[\theta(t)] f_{2}(x, \dot{x})\right\} b \cos \frac{\theta(t)}{2} \\
& \left.+h_{\mathrm{eq}} F(d, \dot{d})+\ddot{u}_{\mathrm{g}}\left\{m \frac{l}{2} \cos [\alpha \operatorname{sgn}[\theta(t)]-\theta(t)]+m_{\mathrm{eq}} h_{\mathrm{eq}}\right\}\right\},
\end{aligned}
$$

where $\operatorname{sgn}($.$) is the sign function, and \varepsilon($.$) is the unit step$ function as follows:

$$
\varepsilon(x)= \begin{cases}0, & x<0 \\ 1, & x \geq 0 .\end{cases}
$$

Equation (17) gives the basic equation governing dynamic responses of the FSCW structure under seismic excitations.

4.2. Mathematical Description of the Hysteresis. From equation (17), it can be seen that the restoring forces of the dampers and frame, i.e., $f_{1}\left(x_{1}, \dot{x}_{1}\right), f_{2}\left(x_{2}, \dot{x}_{2}\right)$, and $F(d, \dot{d})$, need to be expressed explicitly so as to obtain the solution. Again, a bilinear hysteresis shown in Figure 5 is adopted for the frame, and the elastic-perfectly plastic hysteresis is used for the damper.

Note that the elastic-perfectly plastic hysteresis can be seen as a special bilinear hysteresis provided that the postyield stiffness is set to zero. For the bilinear hysteresis illustrated in Figure 14, where $f_{\mathrm{y}}, x_{\mathrm{y}}, k_{\mathrm{s}}$, and $\eta$ represent the yield force, the yield displacement, the elastic stiffness, and the postyield stiffness coefficient, respectively, the restoring force can be written mathematically as follows [36]:

$$
\begin{aligned}
f(x, \dot{x}) & =\eta k_{\mathrm{s}} x+(1-\eta) k_{\mathrm{s}} z, \\
\dot{z} & =\dot{x}\left[1-\varepsilon(\dot{x}) \varepsilon\left(z-x_{\mathrm{y}}\right)-\varepsilon(-\dot{x}) \varepsilon\left(-z-x_{\mathrm{y}}\right)\right],
\end{aligned}
$$

where $z$ is the hysteresis displacement.

For the dampers, when the wall rotates about point $\mathrm{O}^{\prime}$, the displacements of the two dampers are

$$
\begin{aligned}
& x_{1}=-2 b \sin \frac{\theta(t)}{2}, \\
& x_{2}=0 .
\end{aligned}
$$

When the wall rotates about point $\mathrm{O}$, the displacements turn into

$$
\begin{aligned}
& x_{1}=0, \\
& x_{2}=2 b \sin \frac{\theta(t)}{2} .
\end{aligned}
$$




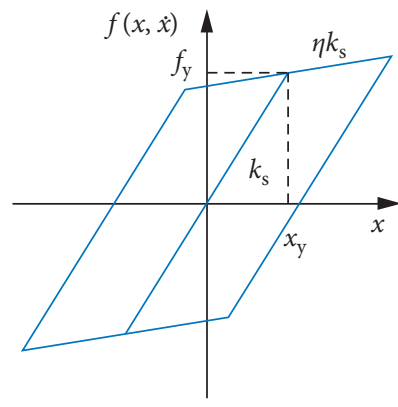

FIGURE 14: Bilinear hysteresis model.

For the frame, the following expression is approximately valid:

$$
d=h_{\mathrm{eq}} \theta(t)
$$

4.3. Consideration of the Impact. When the SC wall returns to the original position, i.e. $\theta=0$, an impact between the wall and the ground occurs. It is assumed that the rotation of the wall changes continuously during the impact. According to the principle of conservation of moment of momentum, the relationship between the angular velocity of the SC wall before and after impact can be determined approximately as follows [5]:

$$
I_{0} \dot{\theta}_{1}-m \dot{\theta}_{1} b \frac{l}{2} \sin \alpha=I_{0} \dot{\theta}_{2}
$$

where $\dot{\theta}_{1}$ and $\dot{\theta}_{2}$ are the angular velocity of the wall before and after the impact, respectively. From the above equation, it can be derived that

$$
k=\frac{\dot{\theta}_{2}}{\dot{\theta}_{1}}=1-\frac{3}{2} \sin ^{2} \alpha,
$$

where $k$ is the ratio between the angular velocity of the SC wall after and before the impact. Note that $k$ is generally smaller than 1.0 since energy is always dissipated during the impact.

4.4. Numerical Simulation. The above sections present the complete description of dynamic behavior of the FSCW structure under seismic excitations. Due to its highly nonlinear nature, the MATLAB/Simulink software is employed here to obtain the numerical solutions [37]. The Simulink model is built as shown schematically in Figure 15. A total of eight subsystems or modules, i.e., the ground excitation module, the SC wall subsystem, the PT tendon subsystem, the frame subsystem, the damper subsystem, two integrator modules, and the output module, are involved in the model. The ground excitation module is used to input the seismic excitations. The main parameters related to the subsystems include: (i) $b, h$, and $m$ (the SC wall subsystem), (ii) $F_{\mathrm{p} 0}$ and $k_{\mathrm{p}}$ (the PT tendon subsystem), (iii) $f_{\mathrm{yf}}, k_{\mathrm{f}}$, and $\eta$ (the frame subsystem), and (iv) $f_{\mathrm{y}}$ and $k_{\mathrm{d}}$ (the damper subsystem). The Integration 1 module is responsible to simulate the impact between the SC wall and the ground by modifying the angular velocity after the impact through the Gain module. For the integration modules, the solver type is chosen to be ode23tb (stiff/TR-BDF2) [37], the time interval is set to be variable and the relative tolerance is set to be 0.001 .

The established Simulink model is further applied to analyze seismic responses of the FSCW structure with the same parameters as given in Section 3.2.2. The EL Centro record shown in Figure 16 is selected as the ground excitation, and its peak value is adjusted to $510 \mathrm{~cm} / \mathrm{s}^{2}$ [38]. The dynamic responses of the FSCW structure, including the time-history curve of the rotation angle of the wall and hysteresis curves of the dampers and the frame, are obtained and plotted in Figures 17(a)-17(d), respectively. It can be seen that the hysteresis of the dampers is elastic-perfectly plastic, and one of the frames is bilinear, showing that the results can properly replicate the hysteresis characteristics of the FSCW structure. Therefore, the Simulink model can be used approximately to predict dynamic responses of the FSCW structure under seismic excitations.

\section{Parametric Study}

In this section, a comprehensive parametric study is conducted using the above Simulink model to investigate the influence of a variety of design parameters on dynamic responses of the FSCW structure under seismic excitations. The rotation angle of the SC wall is selected to represent dynamic responses of the FSCW structure, since it can approximately give some other responses, such as the lateral displacement of the frame (equation (22)).

5.1. Ground Motion Records. A total of seven earthquake records, which include six real earthquake records and an artificial one designated as EQ01-EQ07, respectively, are employed here to conduct the time-history analysis. The properties related to the selected earthquake records are summarized and listed in Table 1. Again, all the records are scaled to have a peak value of $510 \mathrm{~cm} / \mathrm{s}^{2}$ [38].

5.2. Parameter Values Involved in This Study. Six independent design parameters are taken into account, which include the initial force and elastic stiffness of the PT tendon, the yield force and elastic stiffness of the damper, and the yield force and elastic stiffness of the frame. The parameter values involved in this study are listed in Table 2, while the other parameters have the same values as in Section 3.2.2.

\section{Results and Discussions}

6.1. Effect of Parameters concerning the PT Tendon. To investigate the effect of the parameters regarding the PT tendon on seismic responses of the FSCW structure, the parametric analyses are conducted with the values of $F_{\mathrm{p} 0}$ and $k_{\mathrm{p}}$ altered according to Table 2, respectively. The other parameter values are set as follows: $F_{\mathrm{y}}=187.9 \mathrm{kN}, k_{\mathrm{d}}=$ $195.04 \mathrm{kN} / \mathrm{mm}, f_{\mathrm{yf}}=500 \mathrm{kN}$, and $k_{\mathrm{f}}=47 \mathrm{kN} / \mathrm{mm}$. 


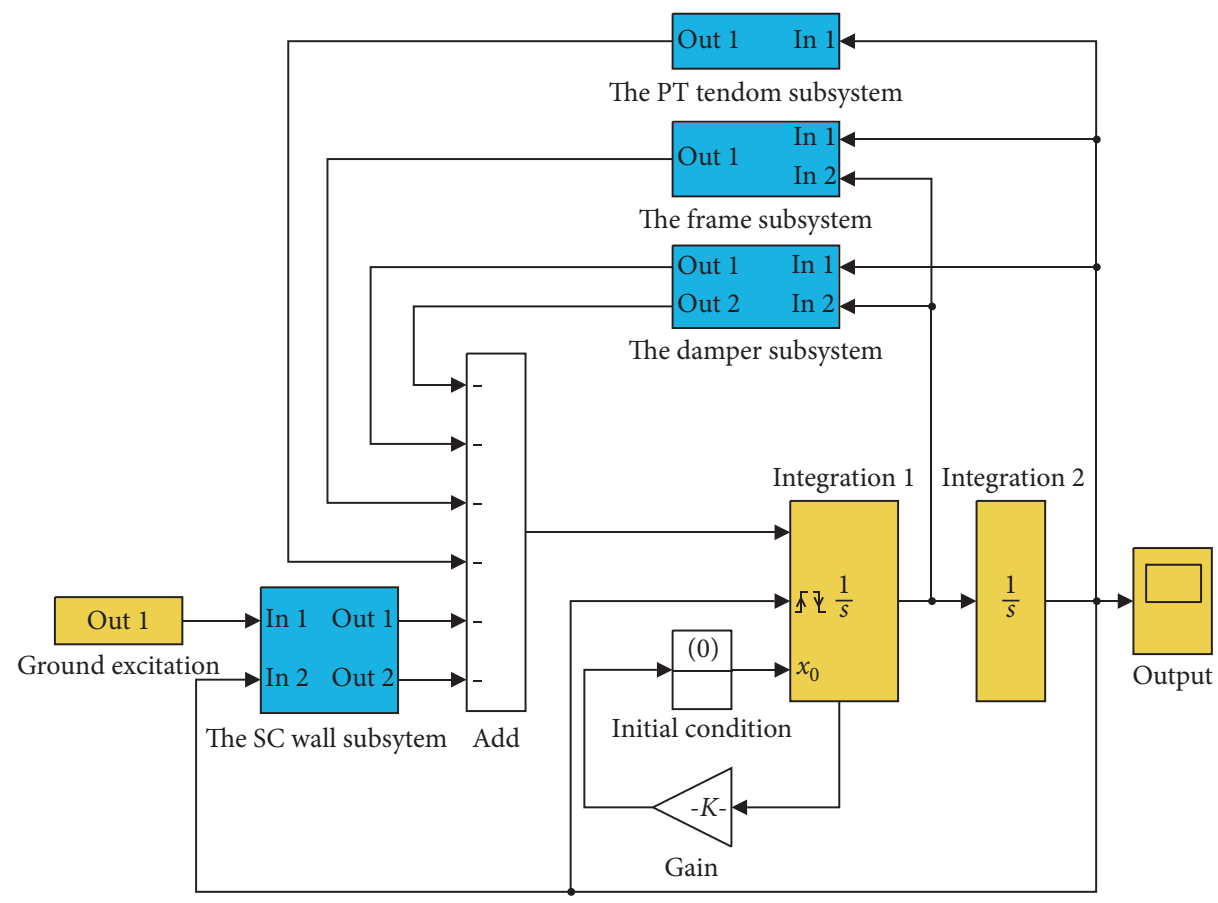

FIGURE 15: Simulink model of the FSCW structure.

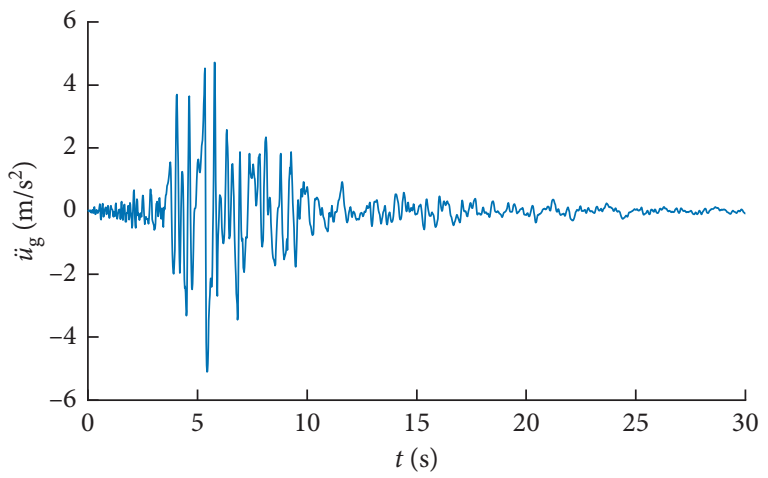

FIgURE 16: EL Centro record used in the analysis.

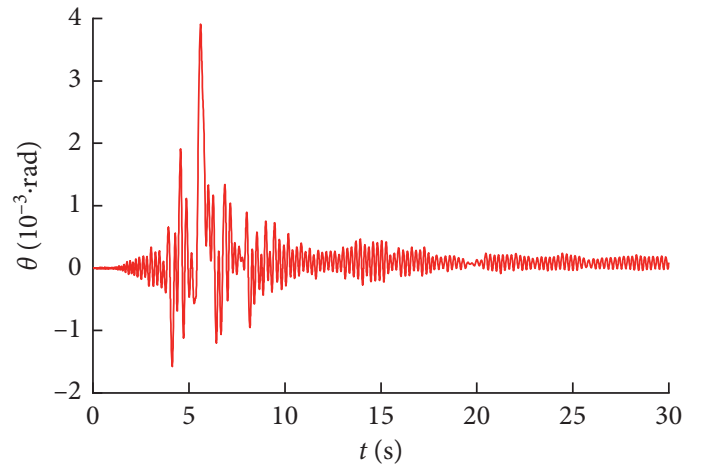

(a)

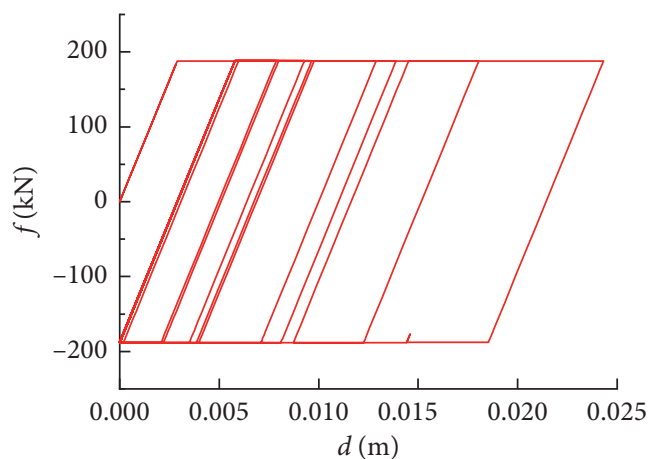

(b)

Figure 17: Continued. 


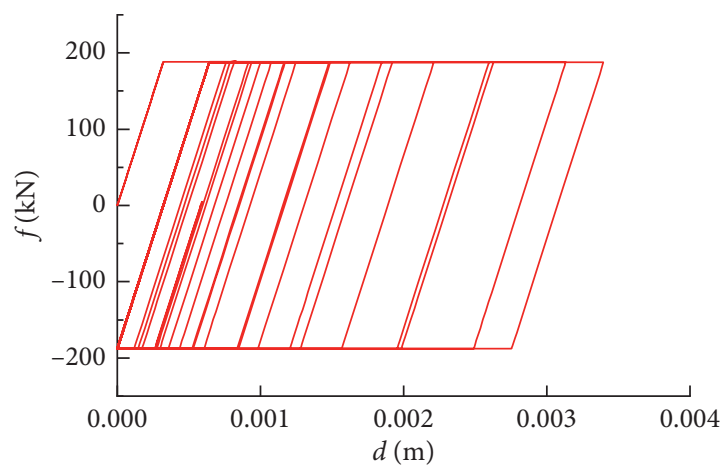

(c)

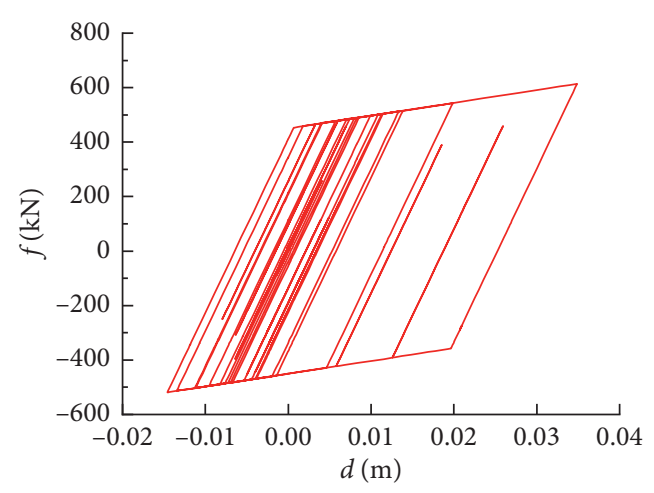

(d)

Figure 17: Dynamic responses of the FSCW structure under seismic excitations. (a) Time-history curve of the rotation angle of the wall; hysteresis curve of (b) the left damper, (c) the right damper, and (d) the frame.

TABLE 1: Earthquake records involved in this study.

\begin{tabular}{lccc}
\hline No. & Record & $\begin{array}{c}\text { Duration } \\
(\mathrm{s})\end{array}$ & $\begin{array}{c}\text { PGA } \\
\left(\mathrm{cm} / \mathrm{s}^{2}\right)\end{array}$ \\
\hline EQ01 & Imperial Valley 1940, EL Centro & 39.98 & 450.03 \\
EQ02 & Imperial Valley 1940, EL Centro & 39.98 & 662.88 \\
EQ03 & Loma Prieta, 1989, Gilroy & 39.98 & 652.49 \\
EQ04 & Loma Prieta, 1989, Gilroy & 39.98 & 950.93 \\
EQ05 & Northridge, 1994, Sylmar & 59.98 & 801.44 \\
EQ06 & North Palm Springs, 1986 & 59.98 & 999.43 \\
EQ07 & - & 40.00 & 510 \\
\hline
\end{tabular}

TABLE 2: Parameter values used in the study.

\begin{tabular}{lcccccc}
\hline \multicolumn{2}{c}{ Parameter } \\
\hline \multirow{2}{*}{ PT } & $F_{\mathrm{p} 0}(\mathrm{kN})$ & 198.46 & 354.7 & 508.08 & 696.76 & 1026.02 \\
tendon & $k_{\mathrm{p}}(\mathrm{kN} / \mathrm{mm})$ & 15.36 & 27.44 & 39.32 & 53.92 & 79.4 \\
\hline \multirow{2}{*}{ Damper } & $F_{\mathrm{y}}(\mathrm{kN})$ & 72.45 & 108.75 & 187.9 & 246.45 & 317.35 \\
& $k_{\mathrm{d}}(\mathrm{kN} / \mathrm{mm})$ & 96.44 & 139.24 & 195.04 & 230.76 & 286.2 \\
\hline \multirow{2}{*}{ Frame } & $f_{\mathrm{yf}}(\mathrm{kN})$ & 300 & 400 & 500 & 600 & 700 \\
& $k_{\mathrm{f}}(\mathrm{kN} / \mathrm{mm})$ & 29 & 38 & 47 & 56 & 65 \\
\hline
\end{tabular}

Figures 18(a) and 18(b) show the maximum rotation angle of the SC wall averaging over the selected records for various values of $F_{\mathrm{p} 0}$ and $k_{\mathrm{p}}$, respectively. In the two cases, $k_{\mathrm{p}}$ and $F_{\mathrm{p} 0}$ are set as $39.32 \mathrm{kN} / \mathrm{mm}$ and $508.08 \mathrm{kN}$, respectively. It can be seen that the maximum rotation angle of the SC wall decreases obviously with the increase of $F_{\mathrm{p} 0}$ while changing little with the increase of $k_{\mathrm{p}}$. Therefore, improving the initial force of the PT tendon has a beneficial effect on restraining seismic responses of the FSCW structure in terms of the rotation angle of the SC wall, while the elastic stiffness of the PT tendon has little effect.

6.2. Effect of Parameters concerning the Dampers. In the parametric analyses regarding the dampers, the values of $F_{\mathrm{y}}$ and $k_{\mathrm{d}}$ are changed according to Table 2, respectively. The other parameter values are taken as follows: $F_{\mathrm{p} 0}=508.08 \mathrm{kN}, k_{\mathrm{p}}=39.32 \mathrm{kN} / \mathrm{mm}, f_{\mathrm{yf}}=500 \mathrm{kN}$, and $k_{\mathrm{f}}=$ $47 \mathrm{kN} / \mathrm{mm}$.
Figures 19(a) and 19(b) show the maximum rotation angle of the SC wall averaging over the selected records for various values of $F_{\mathrm{y}}$ and $k_{\mathrm{d}}$, respectively. For the two cases, the values of $k_{\mathrm{d}}$ and $F_{\mathrm{y}}$ are set as $195.04 \mathrm{kN} / \mathrm{mm}$ and $187.9 \mathrm{kN}$, respectively. It can be seen that, on the whole, the maximum rotation angle of the SC wall decreases as $F_{\mathrm{y}}$ or $k_{\mathrm{d}}$ increases. Therefore, increasing the yield force or the elastic stiffness of the damper can help lower seismic responses of the FSCW structure in terms of the rotation angle of the SC wall.

6.3. Effect of Parameters concerning the Frame. In the parametric analyses regarding the frame, the values of $f_{\mathrm{yf}}$ and $k_{\mathrm{f}}$ are varied according to Table 2, respectively. The other parameter values are taken as follows: $F_{\mathrm{p} 0}=508.08 \mathrm{kN}$, $k_{\mathrm{p}}=39.32 \mathrm{kN} / \mathrm{mm}, F_{\mathrm{y}}=187.9 \mathrm{kN}$, and $k_{\mathrm{d}}=195.04 \mathrm{kN} / \mathrm{mm}$.

Figures 20(a) and 20(b) show the maximum rotation angle of the SC wall averaging over the selected records for various values of $f_{\mathrm{yf}}$ and $k_{\mathrm{f}}$, respectively. For the two cases, the values of $k_{\mathrm{f}}$ and $f_{\mathrm{yf}}$ are set as $47 \mathrm{kN} / \mathrm{mm}$ and $500 \mathrm{kN}$, respectively. It can be seen that the maximum rotation angle of the SC wall falls abruptly as $f_{\mathrm{yf}}$ or $k_{\mathrm{f}}$ increases. For example, as $f_{\mathrm{yf}}$ changes from $300 \mathrm{kN}$ to $700 \mathrm{kN}$, the maximum rotation angle drops by about $40.80 \%$. Therefore, increasing the yield force or the elastic stiffness of the frame can remarkably reduce seismic responses of the FSCW structure in terms of the rotation angle of the SC wall.

\section{Conclusions}

In this paper, a simplified analysis model of the FSCW structure is first proposed. After validated by the FE analysis method, the model is further utilized to establish motion equations of the FSCW structure under seismic excitations. By way of numerical simulation, seismic responses of the FSCW structure are obtained. Finally, a comprehensive parametric study is conducted to study the influence of a variety of design parameters on seismic responses of the FSCW structure. Based on the findings of this study, the following conclusions can be drawn: 


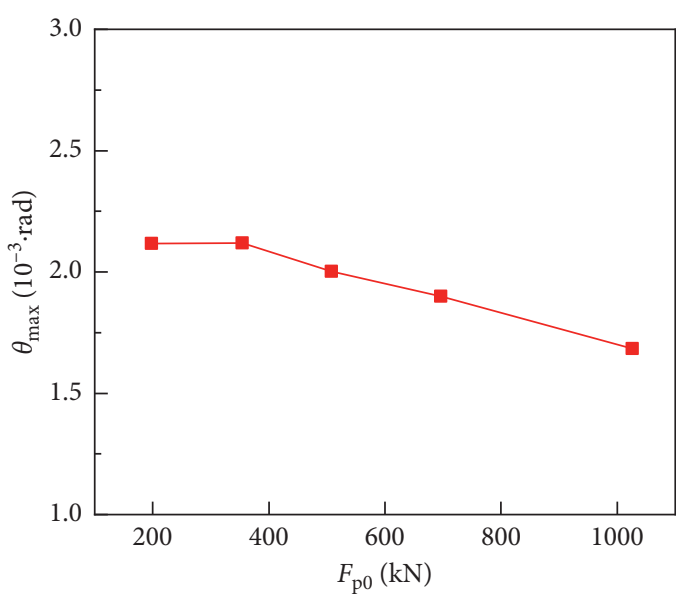

(a)

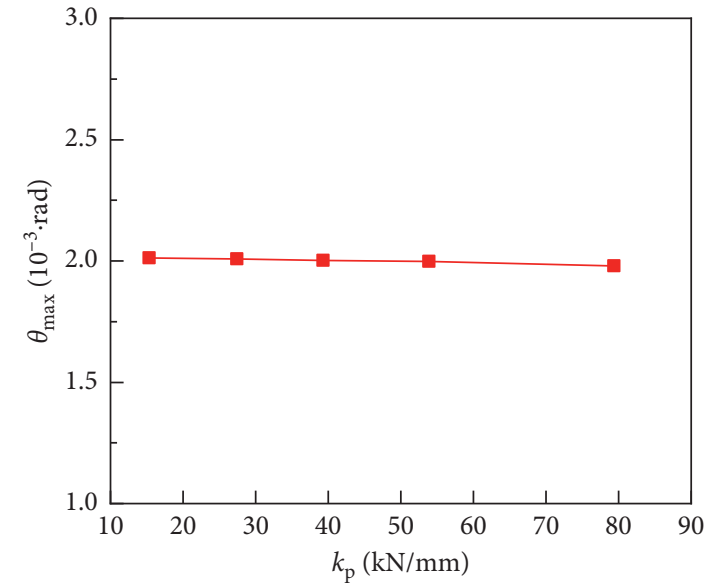

(b)

Figure 18: Effects of the parameters regarding the PT tendon. (a) $F_{\mathrm{p} 0}$. (b) $k_{\mathrm{p}}$.

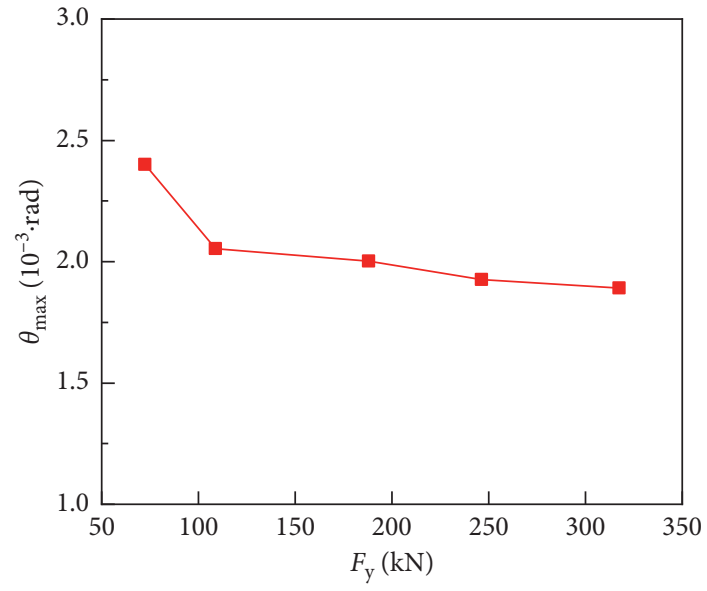

(a)

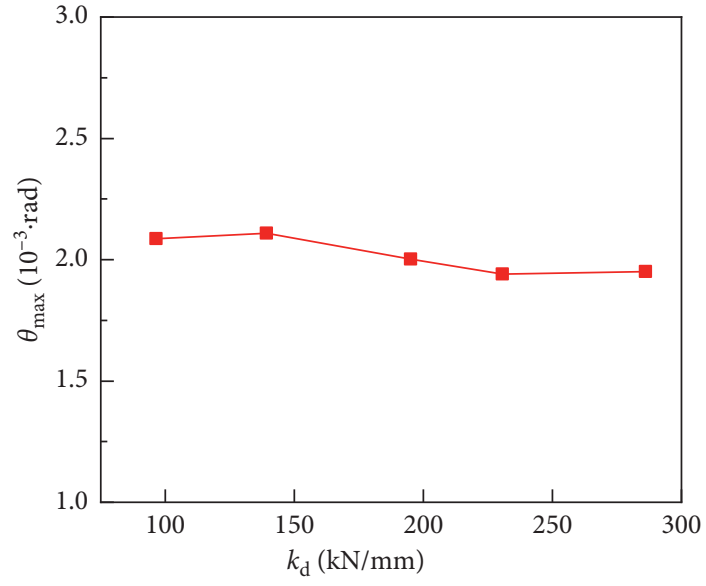

(b)

FIGURE 19: Effects of the parameters regarding the dampers. (a) $F_{\mathrm{y}}$. (b) $k_{\mathrm{d}}$.

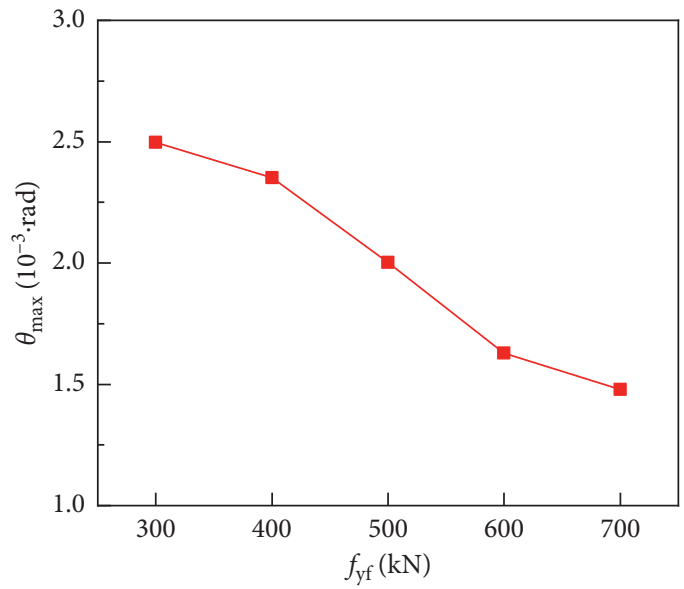

(a)

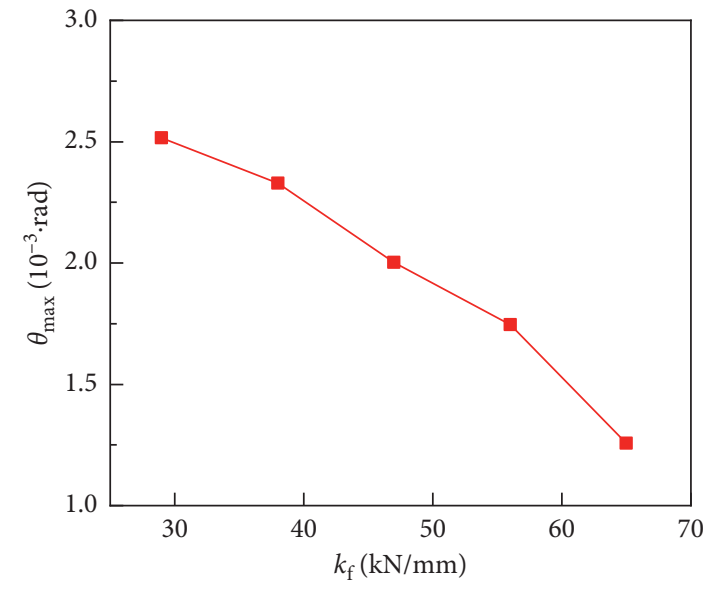

(b)

FIGURE 20: Effects of the parameters regarding the frame. (a) $f_{\mathrm{yf}}$ (b) $k_{\mathrm{f}}$. 
(1) The proposed simplified analysis model of the FSCW structure can be approximately used to capture the nonlinear behavior of the FSCW structure under lateral loading, while having the great advantage of high computational efficiency. Based on the simplified analysis model, seismic responses of the FSCW structure can be obtained by solving numerically the motion equations of the FSCW structure under seismic excitations.

(2) Within the parameter values considered in this study, improving the yield force or elastic stiffness of the frame can remarkably mitigate seismic responses of the FSCW structure in terms of the rotation angle of the SC wall. In addition, increasing the initial force of the PT tendon, as well as the yield force or elastic stiffness of the damper, has also a beneficial effect.

\section{Data Availability}

The data used to support the findings of this study are included within the article.

\section{Disclosure}

Any opinions, findings, and conclusions or recommendations expressed in this study are those of the authors and do not necessarily reflect the views of the National Science Foundation of China.

\section{Conflicts of Interest}

The authors declare that they have no conflicts of interest.

\section{Acknowledgments}

This work was supported by the National Natural Science Foundation of China under grant no. 51578429. The financial support is gratefully acknowledged.

\section{References}

[1] Y. C. Kurama, Seismic analysis, behavior, and design of unbonded post-tensioned precast concrete walls, Ph.D. dissertation, Lehigh University, Bethlehem, PA, USA, 1997.

[2] N. S. Armouti, Seismic performance of precast concrete structural walls, Ph.D. dissertation, Lehigh University, Bethlehem, PA, USA, 1993.

[3] G. W. Housner, "The behavior of inverted pendulum structures during earthquakes," Bulletin of the Seismological Society of America, vol. 53, no. 2, pp. 403-417, 1963.

[4] C.-S. Yim, A. K. Chopra, and J. Penzien, "Rocking response of rigid blocks to earthquakes," Earthquake Engineering \& Structural Dynamics, vol. 8, no. 6, pp. 565-587, 1980.

[5] J. Zhang and N. Makris, "Rocking response of free-standing blocks under cycloidal pulses," Journal of Engineering $\mathrm{Me}$ chanics, vol. 127, no. 5, pp. 473-483, 2001.

[6] N. Makris and J. Zhang, "Rocking response of anchored blocks under pulse-type motions," Journal of Engineering Mechanics, vol. 127, no. 5, pp. 484-493, 2001.

[7] A. Di Egidio, D. Zulli, and A. Contento, "Comparison between the seismic response of $2 \mathrm{D}$ and $3 \mathrm{D}$ models of rigid blocks," Earthquake Engineering and Engineering Vibration, vol. 13, no. 1, pp. 151-162, 2014.

[8] X. Hu, Q. Lu, and Y. Yang, "Rocking response analysis of selfcentering walls under ground excitations," Mathematical Problems in Engineering, vol. 2018, Article ID 4371585, 12 pages, 2018.

[9] Y. C. Kurama, S. Pessiki, R. Sause, L. W. Lu, and M. T. El-Sheikh, "Analytical modeling and lateral load behavior of unbonded post-tensioned precast concrete walls," Research Report No.EQ-96-02, Lehigh University, Bethlehem, PA, USA, 1998.

[10] Y. C. Kurama, "Seismic design of unbonded post-tensioned precast concrete walls with supplemental viscous damping," ACI Structural Journal, vol. 97, no. 4, pp. 648-658, 2000.

[11] L. A. Toranzo, The use of rocking walls in confined masonry structures: a performance-based approach, Ph.D. dissertation, University of Canterbury, Christchurch, New Zealand, 2002.

[12] L. A. Toranzo, J. I. Restrepo, J. B. Mander, and A. J. Carr, "Shake-table tests of confined-masonry rocking walls with supplementary hysteretic damping," Journal of Earthquake Engineering, vol. 13, no. 6, pp. 882-898, Jul. 2009.

[13] F. J. Perez, Experimental and analytical lateral load response of unbonded post-tensioned precast concrete walls, Ph.D. dissertation, Lehigh University, Bethlehem, PA, USA, 2004.

[14] F. J. Perez, S. Pessiki, and R. Sause, "Lateral load behavior of unbonded post-tensioned precast concrete walls with vertical joints," PCI Journal, vol. 49, no. 2, pp. 48-64, 2004.

[15] F. J. Perez, S. Pessiki, and R. Sause, "Seismic design of unbonded post-tensioned precast concrete walls with vertical joint connectors," PCI Journal, vol. 49, no. 1, pp. 58-79, 2004.

[16] F. J. Perez, S. Pessiki, and R. Sause, "Experimental lateral load response of unbonded post-tensioned precast concrete walls," ACI Structural Journal, vol. 110, no. 6, pp. 1045-1056, 2013.

[17] J. I. Restrepo and A. Rahman, "Seismic performance of selfcentering structural walls incorporating energy dissipators," Journal of Structural Engineering, vol. 133, no. 11, pp. 15601570, 2007.

[18] B. Erkmen and A. E. Schultz, "Self-centering behavior of unbonded, post-tensioned precast concrete shear walls," Journal of Earthquake Engineering, vol. 13, no. 7, pp. 10471064, Sep. 2009.

[19] L. Pakiding, S. Pessiki, R. Sause, and M. Rivera, "Lateral load response of unbonded post-tensioned cast-in-place concrete walls," in Proceedings of Structures Congress 2015, Reston, VA, USA, 2015.

[20] L. Panian, M. Steyer, and S. Tipping, "Post-tensioned concrete walls for seismic resistance," Journal of the Post-Tensioning Institute, vol. 5, no. 1, pp. 7-12, 2007.

[21] B. J. Smith, Y. C. Kurama, and M. J. McGinnis, "Design and measured behavior of a hybrid precast concrete wall specimen for seismic regions," Journal of Structural Engineering, vol. 137, no. 10, pp. 1052-1062, 2011.

[22] B. J. Smith, Y. C. Kurama, and M. J. McGinnis, "Behavior of precast concrete shear walls for seismic regions: comparison of hybrid and emulative specimens," Journal of Structural Engineering, vol. 139, no. 11, pp. 1917-1927, 2013.

[23] C. E. Grigorian and M. Grigorian, "Performance control and efficient design of rocking-wall moment frames," Journal of Structural Engineering, vol. 142, no. 2, article 04015139, 2016.

[24] M. Grigorian and C. Grigorian, "An introduction to the structural design of rocking wall-frames with a view to collapse prevention, self-alignment and repairability," Structural 
Design of Tall and Special Buildings, vol. 25, no. 2, pp. 93-111, 2016.

[25] A. Wada, Z. Qu, H. Ito, S. Motoyui, H. Sakata, and K. Kasai, "Seismic retrofit using rocking walls and steel dampers," in Proceedings of Improving the Seismic Performance of Existing Buildings and Other Structures, Reston, VA, USA, 2009.

[26] Z. Qu, A. Wada, S. Motoyui, H. Sakata, and S. Kishiki, "Pinsupported walls for enhancing the seismic performance of building structures," Earthquake Engineering \& Structural Dynamics, vol. 41, no. 14, pp. 2075-2091, 2012.

[27] J. J. Ajrab, G. Pekcan, and J. B. Mander, "Rocking wall-frame structures with supplemental tendon systems," Journal of Structural Engineering, vol. 130, no. 6, pp. 895-903, 2004.

[28] H. Zibaei and J. Mokari, "Evaluation of seismic behavior improvement in RC MRFs retrofitted by controlled rocking wall systems," The Structural Design of Tall and Special Buildings, vol. 23, no. 13, pp. 995-1006, 2014.

[29] X. Hu, Y. Zhang, and N. S. Moghaddasi, "Seismic performance of reinforced concrete frames retrofitted with selfcentering hybrid wall," Advances in Structural Engineering, vol. 15, no. 12, pp. 2131-2143, 2012.

[30] M. Grigorian, A. S. Moghadam, H. Mohammadi, and M. Kamizi, "Methodology for developing earthquake-resilient structures," Structural Design of Tall and Special Buildings, vol. 28, no. 2, 2018.

[31] T. Pauley and M. J. N. Priestley, Seismic Design of Reinforced Concrete and Masonry Buildings, John Wiley \& Sons, Inc., Hoboken, NJ, USA, 2009.

[32] M. J. N. Priestley, G. M. Calvi, M. J. Kowalsky, and G. H. Powell, "Displacement-based seismic design of structures," Earthquake Spectra, vol. 24, no. 2, pp. 555-557, 2007.

[33] Dassault Systèmes, “Abaqus analysis user's guide," 2016, http:// dsk.ippt.pan.pl/docs/abaqus/v6.13/books/usb/default.htm.

[34] Ministry of Construction of the People's Republic of China, GB50010-2010 Code for Design of Concrete Structures, China Architecture \& Building Press, Beijing, China, 2010, in Chinese.

[35] H. A. Spieth, A. J. Carr, A. G. Murahidy et al., "Modelling of post-tensioned precast reinforced concrete frame structures with rocking beam-column connections," in Proceedings of New Zealand Society of Earthquake Engineering Conference 2004, New Zealand, 2004.

[36] L. D. Lutes and S. Sarkani, Random Vibrations: Analysis of Structural and Mechanical Systems, Elsevier ButterworthHeinemann, Burlington, MA, USA, 2004.

[37] Mathworks, "MATLAB/simulink," 2014, https://www.mathworks. com/products/simulink.html.

[38] Ministry of Construction of the People's Republic of China, GB50011-2010 Code for Seismic Design of Buildings, China Architecture \& Building Press, Beijing, China, 2010, in Chinese. 


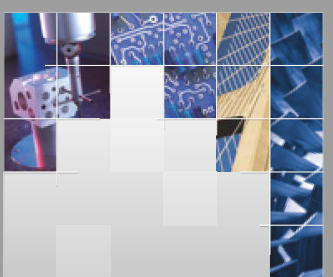

\section{Enfincering}
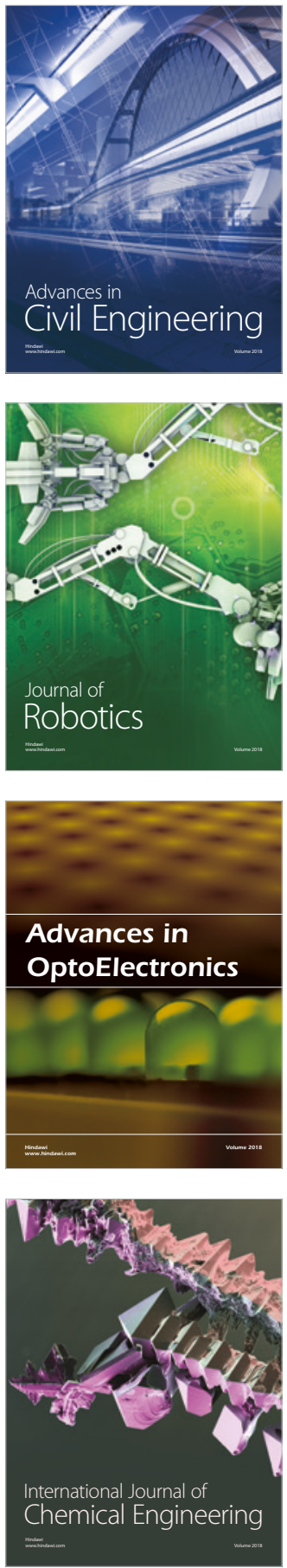

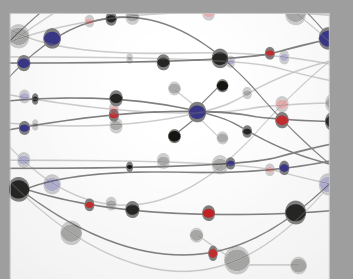

\section{Rotating \\ Machinery}

The Scientific World Journal

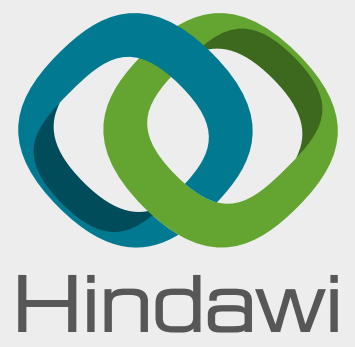

Submit your manuscripts at

www.hindawi.com
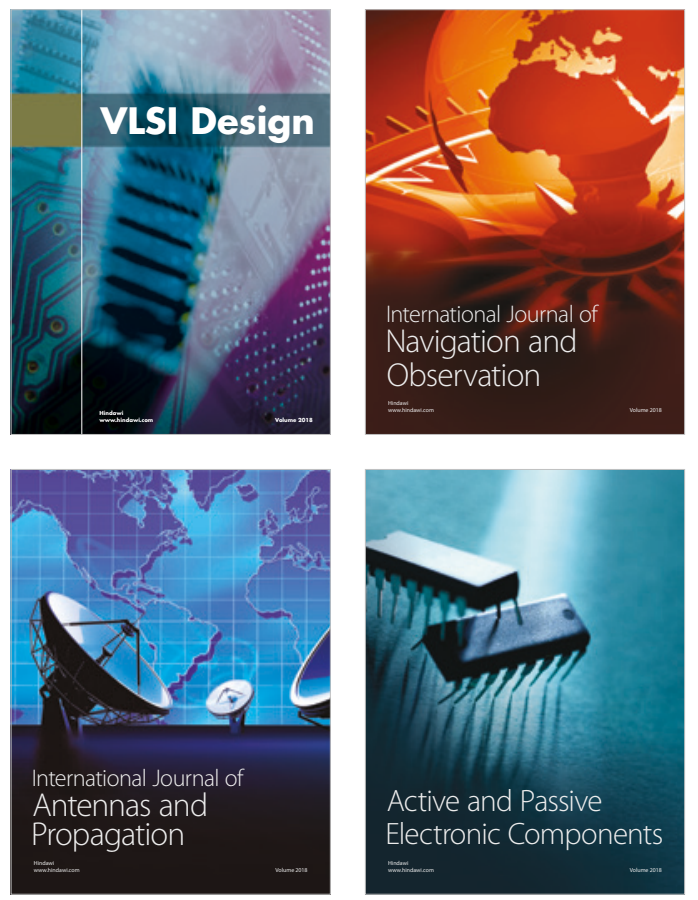
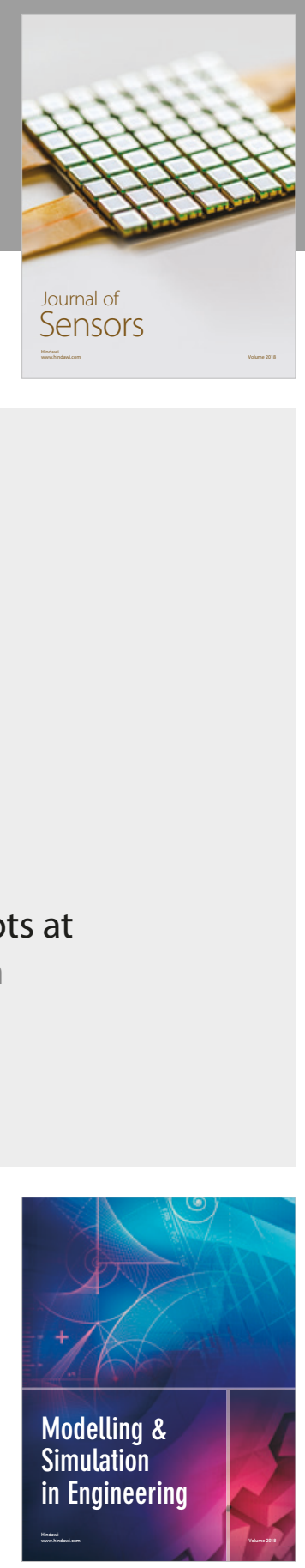

\section{Advances \\ Multimedia}
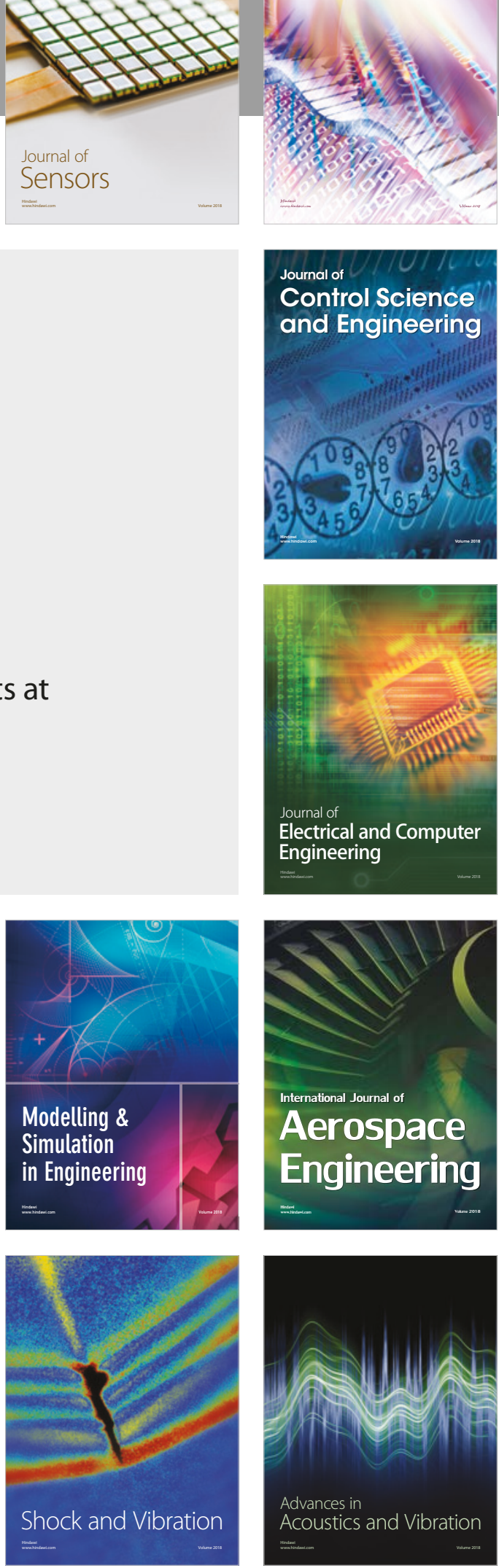